\title{
Viajantes europeus nas colônias italianas
}

\author{
European travellers in the Italian colonies
}

\author{
Vania Beatriz M. Herédia*
}

\begin{abstract}
Resumo: A proposta desse estudo é analisar as cartas escritas por um viajante europeu que veio ao Rio Grande do Sul numa missão religiosa com intuito de verificar as condições de espiritualidade nas colônias italianas. Esse viajante era um homem apostólico, empreendedor e considerado pela ordem religiosa que participava um estrategista conhecido. Dessa forma, o estudo de suas cartas abre a possibilidade de conhecer suas impressões sobre as colônias italianas bem como as estratégias que delineou para a fundação da missão capuchinha no Rio Grande do Sul. As cartas foram extraídas da obra A Igreja e os Capuchinhos do Rio Grande do Sul, de 1895-1909, escritas por Frei Bruno de Gillonnay, no total de quinze cartas, e, compreendem desde a partida de Bordeaux, o desembarque no Porto de Rio Grande, a chegada em Porto Alegre, o percurso para Garibaldi, as impressões que esse estrangeiro tem das colônias italianas e da forma que as descreve para seus superiores, explicitando os locais como a terra da liberdade e do futuro trabalho que teriam para se instalar nessas colônias.
\end{abstract}

Palavras-chave: Viajantes europeus. Missões dos Capuchinhos. Estudos regionais.

Abstract: The proposal of this study is to analyze letters written by a European traveler who came to Rio Grande do Sul on a religious mission in order to verify the spirituality conditions in the Italian colonies. This traveler was an apostolic man, an entrepreneur, and considered to be a strategist by the religious order of which he was a participant. The study of his letters opens the possibility to learn about his impressions about the Italian colonies in the State of Rio Grande do Sul as early as in the $19^{\text {th }}$ century, and also the strategies he outlined to found the Capuchin mission in the State. The letters were taken from the book A Igreja e os Capuchinhos do Rio Grande do Sul, de 1895-1909, by fr Bruno de Gillonnay, and they comprehend the trip the clergyman took since his departure from Bordeaux, France, his disembarkation at the Port of Rio Grande, arrival in Porto Alegre, the trip to Garibaldi, up to the impressions that this foreigner had of the Italian colonies. Through these letters it can be seen how the founder of the Capuchin mission describes to his superiors the atmosphere in the colonies, the religious sense present in the actions of the settlers, and the perspective of future, which qualifies the places of arrival as the land of liberty and future for the religious mission in those colonies.

Keywords: European travelers. Capuchin mission. Regional study.

\footnotetext{
* Doutora em História das Américas pela Universidade de Gênova - Itália (1992) e PósDoutora pela Universidade de Pádua (2003). Professora Titular na Universidade de Caxias do Sul.
} 
A proposta deste estudo é analisar as cartas escritas por um viajante europeu que veio ao Rio Grande do Sul, numa missão religiosa e com o intuito de verificar as condições de espiritualidade nas colônias italianas. Esse viajante era um homem apostólico, empreendedor e considerado pela ordem religiosa de que participava um estrategista conhecido. Dessa forma, o estudo de suas cartas abre a possibilidade de conhecer suas impressões sobre as colônias italianas, bem como as estratégias que delineou para a fundação da missão capuchinha no Rio Grande do Sul.

As cartas foram extraídas da obra A Igreja e os Capuchinhos do Rio Grande do Sul, de 1895-1909, escritas por Frei Bruno de Gillonnay, e compreendem o percurso desde sua partida de Bordeaux, França, o desembarque no Porto de Rio Grande, a chegada em Porto Alegre, a viagem para Garibaldi, até as impressões que esse estrangeiro tem das colônias italianas e a forma como as descreve para seus superiores, qualificando os locais como a terra da liberdade e o futuro trabalho que teriam para se instalar nessas colônias.

Talvez as cartas desse protagonista não sejam o único fator que influenciou a vinda dos missionários Capuchinhos franceses para o Brasil no final do século XIX. Entretanto, a descrição feita por Bruno de Gillonnay sobre as colônias italianas no Rio Grande do Sul pode ter determinado, além da vinda, outras ações que acabaram solidificando a presença dos Capuchinhos no Rio Grande do Sul. Bruno de Gillonnay é considerado o fundador da Missão Capuchinha no Rio Grande do Sul e teve um papel importante na formação religiosa das colônias italianas no Sul do Brasil. Sua vinda ao Brasil ocorreu a convite do Bispo Dom Cláudio J. Gonçalves Ponce de Leão que, na época, estava preocupado em "obter missionários que se ocupassem dos imigrantes italianos". (Gillonnay; D’apremont, 1976, p. 225).

$\mathrm{O}$ presente estudo foi dividido em dois momentos, tendo como foco de análise os relatos sobre as colônias no Sul do Brasil. O primeiro trata da contextualização das colônias italianas, e o segundo, das impressões registradas nas cartas acerca da missão dos Capuchinhos no Sul do Brasil.

\section{As colônias italianas vistas pelos missionários}

É interessante observar que a forma de contextualizar o Estado do Rio Grande do Sul é feita por meio de uma descrição geográfica, pontuando latitude, extensão da superfície e, principalmente, detalhes sobre o clima. Os dados geográficos relatados nas cartas permitem 
visualizar a questão do solo para o plantio, a presença dos indígenas e a ocupação da terra pelos portugueses.

Evidenciam que "os indígenas continuaram donos de toda a região até 1622 , cento e vinte e dois anos depois do descobrimento do Brasil. Nessa data, os jesuítas, vindos da Argentina, penetraram, através do oeste, e iniciaram a evangelização dos indígenas da região" (Gillonnay; D’apremont, 1976, p. 224).

A visão que foi repassada aos religiosos, antes de migrarem, é posta como um meio para compreenderem o ambiente em que atuarão como filhos da Província dos Capuchinhos de Sabóia. O Rio Grande do Sul é visto como um campo de futuro, marcado pela presença da riqueza material e espiritual, justificado na seguinte descrição: "Além do pastoreio em grande escala e da agricultura, principais fontes de progresso até o momento, inicia-se a exploração de minas de carvão, [...] e instalam-se fábricas de tecelagem" (Gillonnay; D’apremont, 1976, p. 225).

O percurso desses missionários foi o mesmo que muitos imigrantes fizeram. Passavam pelo Rio de Janeiro, onde havia um serviço de orientação à imigração e colonização, com destino a Montevidéu ou a Buenos Aires, e muitos europeus desembarcavam em Rio Grande, Brasil, onde começavam o percurso terrestre até o destino. Desde a solicitação do bispo para a instalação de uma missão religiosa até a edição do Decreto da Sagrada Congregação dos Assuntos Extraordinários, pelo Papa Leão XIII, a vinda de novas congregações era apenas um desejo. Entretanto, por meio desse decreto, a Província de Saboia tinha a missão de instalar conventos regulares, o que a fez promover a vinda de um provincial juntamente com dois missionários para cumprir tal meta. $\mathrm{O}$ embarque dos mesmos aconteceu em Bordeaux, alguns meses antes da assinatura do decreto pelo Papa Leão XIII que entregava a Missão do Rio Grande à Província de Saboia. O destino era a Colônia Conde D’Eu, ou Alfredo Chaves.

Vale lembrar que a Colônia Conde D’Eu e a Colônia Dona Isabel foram as duas primeiras colônias oficiais "fundadas pelo governo provincial em 1869" (Manfroi, 1975, p. 75), sendo que essas colônias se desenvolveram apenas em 1875 com a chegada dos imigrantes italianos.

A Província de São Pedro havia recebido pela Lei Geral 514, de 1848, 36 léguas quadradas para ocupar com a colonização provincial. Essas terras foram doadas antes da Lei de Terras, de 1850, o que fez com que o governo provincial criasse uma lei em 1851, para adequar à lei anterior, definindo a medição de lotes de 100 mil braças quadradas nas terras que lhe foram entregues pelo Império (De Boni; Costa, 1984, p. 63). 
Em 1869, a província solicitou ao governo imperial a concessão de mais duas glebas com o intuito de continuar o programa de colonização. A concessão de 32 léguas quadradas fez com que as Colônias Conde D'Eu e Dona Isabel fossem fundadas.

Com a ocupação das terras nas colônias criadas, os imigrantes "começaram a atravessar o rio das Antas, e o governo criou a Colônia Alfredo Chaves" (De Boni; Costa, 1984, p. 65). A data de ocupação dessa colônia foi no ano de 1884, ano em que Caxias foi emancipada da situação colonial, tornando-se $5^{\circ}$ Distrito de São Sebastião do Caí.

É importante observar que, em 1888, "foi aprovado pelo Papa Leão XIII a "Propaganda Fide", que previa o regulamento das congregações de missionários para os emigrantes que se dispunham a promover a "obra de evangelização dos filhos da miséria e do trabalho", dando início ao que chamavam "guerra de reconquista das almas perdidas nas regiões extremas do novo mundo" (Rosoli, 1996, p. 34).

Com a intensificação dos fluxos transoceânicos, numerosas ordens e congregações enviaram os seus membros para a América, para assistir seus imigrantes, devido às solicitações de bispos ou de comunidades. A Federação das Congregações Masculinas e Femininas, em 1909, fez com que muitos aderissem à "Itálica Gens" (Rosoli, 1996, p. 39). "Dos anos de 1700 ao final dos anos de 1800, os capuchinhos enviaram 636 religiosos da Itália prevalentemente para evangelizar as populações indígenas" (Rosoli, 1996, p. 40).

A ação da Igreja entre os emigrantes se qualifica a partir de uma tripla função: religiosa, socioassistencial e identitária.

A característica religiosa é constituída pela missão da igreja, de manter a fé dos imigrantes perante as dificuldades sociais e religiosas do primeiro impacto, causado pelo processo emigratório. $\mathrm{O}$ empenho social da Igreja entre os emigrantes, expresso em particular no grande impulso dado ao setor assistencial, à medida que se depararam graves dificuldades materiais e morais. A função identitária se faz pela expressão ativada da língua, da cultura para fins culturais e em segundo lugar da função de integração e coesão para fins de manutenção das comunidades étnicas (Rosoli, 1996, p. 29).

Rosoli chama a atenção para este fato: principalmente nos países americanos, os italianos estavam completamente abandonados do ponto de vista religioso. Rosoli destaca em seus estudos que na 
América do Sul, sobretudo no Brasil, as condições dos italianos eram muito difíceis, especialmente pela sua dispersão nos vastos e isolados territórios, devido à resistência dos fazendeiros dos estados centrais pela prática regular dos assalariados, a extrema escassez de clero e a apatia dos párocos locais (Rosoli, 1996, p. 32).

Essa colocação mostra a preocupação por parte do Clero de estimular missões religiosas que pudessem atender às colônias europeias. A religião foi um fator fundamental de integração e de identidade cultural.

A religiosidade dos imigrantes permaneceu substancialmente aquela que eles trouxeram do país natal com frequência devocional e formalística, às vezes misturada com crenças supersticiosas e práticas mágicas, mas capazes de transmitir o credo religioso e de refinar o confronto com experiências diversas (Rosoli, 1996, p. 36).

A Igreja mostrou ser um fator de agregação das comunidades étnicas. As instituições religiosas comunitárias tinham uma "função de mediação cultural a respeito da Igreja, nas sociedades locais, e de identificação étnica nos confrontos dos grupos e da sociedade global" (Rosoli, 1996, p. 36).

\section{Impressões do missionário sobre as colônias italianas no Sul do Brasil}

Com missão definida pela ordem religiosa francesa, a pedido do bispo de Porto Alegre, Frei Raphael de la Roche, Frei Bruno de Gillonnay e Frei León de Montsapey chegaram ao Rio de Janeiro, em 22 de dezembro de 1895, com passagem para Rio Grande e após para Porto Alegre. Frei Bruno de Gillonnay havia partido de Bourdeaux, passado por Lisboa e permanecido em Formiga, perto de Porto, ${ }^{1}$ que, segundo seus relatos, estava em "efervescência", ${ }^{2}$ o que o levou a seguir diretamente para o Rio de Janeiro.

1 Nas primeiras cartas que Frei Bruno escreveu ao seu superior, pedia licença para comprar um dicionário, uma gramática e uma obra para ajudar nas traduções e nos sermões, o que denota uma dificuldade com a língua portuguesa. Quando trata da língua portuguesa, diz que a mesma é "abundante em palavras que são necessárias saber".

2 Na primeira carta escrita ao Provincial, Frei Bruno de Gillonnay, diz: "Eu embarcarei imediatamente, até aqui tudo foi bem... Mas pelo que se diz, Lisboa está em efervescência. Foi-me aconselhado de lá não descer. No entanto, eu tentarei a sorte, e se o Patriarca não quiser me abrigar, farei velas imediatamente para o Rio de Janeiro. A necessidade desconhece a lei. No Rio de Janeiro eu desembarcarei junto aos capuchinhos italianos." (Bordeaux, 20 de setembro de 1895) 
A vinda dos religiosos tinha dois objetivos que, além de atuarem como missionários nas colônias de italianos, deveriam preparar as condições para receber estudantes Capuchinhos franceses que estavam no Líbano e também cidadãos franceses que sofressem perseguições na própria França. É importante lembrar que o governo francês havia suprimido os privilégios que usufruíam as congregações religiosas, incluindo a obrigatoriedade do serviço militar em território francês. Essa lei isentava apenas os jovens que estivessem no Exterior, com idade entre 19 e 30 anos.

Diante desse contexto, a missão se direcionava para o novo mundo onde muito poderia ser feito, com base na experiência da comunidade capuchinha que estava no Líbano. Na em comparação capital da Província, Porto Alegre, receberam orientações do Bispo Dom Cláudio sobre as colônias italianas. A escolha entre a Conde D'Eu e a Alfredo Chaves cabia aos viajantes.

O Bispo havia dado liberdade de escolha acerca do lugar, mas havia alertado que, na Colônia Conde D'Eu "nenhum padre conseguiu permanecer por muito tempo" (Gillonnay; D'apremont, 1976, p. 226). A descrição da viagem é interessante, pois mostra que os dados geográficos estudados antes da partida se haviam transformado numa visão real da sociedade, e que denotavam diferenças substanciais entre o que haviam visto nos mapas com o que enfrentavam na realidade, conforme relato:

Partimos de Porto Alegre, com estas informações equívocas, a 16 de janeiro de 1896. Sem destino definitivo e sem conhecer o caminho, sem meios de transporte regularmente estabelecidos, que podíamos fazer se não tomar coragem e abandonar-nos à Divina Providência? O primeiro dia foi o melhor. Subindo o Caí, rio de curso tranquilo e de margens graciosas, o pequeno vapor nos desembarcou em São João de Montenegro uma hora antes de anoitecer. De lá sobravamnos ainda $66 \mathrm{~km}$ para chegar a Conde d"Eu. A estrada nada mais era que uma sucessão de barrancos, impossível de os imaginar na Europa. Por esta estrada passavam os produtos da região colonial, transportados no lombo de burros ou em carroças elementares, puxadas por um terno de 8 burros (Gillonnay; D'apremont, 1976, p. 226).

Na época, os viajantes enfrentavam as precárias condições das estradas e dos transportes. A carta remete a 1896, o que significa que, desde a chegada dos alemães, se passaram 72 anos e da chegada dos italianos, 21 anos. Mesmo assim, a ocupação da Região Nordeste do Estado do Rio Grande do Sul era recente, e as dificuldades evidentes. 
A impressão na chegada à Conde D'Eu foi marcada pela sensação de que havia muito a ser feito. Essa colônia recém-fundada, foi prestigiada pelo nome do genro do Imperador, e sua fisionomia delineada pelo trabalho dos imigrantes. Segundo Gillonnay e D’Apremont,

a pequena vila tinha uma população de, mais ou menos, 1000 habitantes; apresentava um relativo bem-estar. Ao redor deste modesto centro, num raio de 10 a $20 \mathrm{Km}$, habitavam os colonos. Cada qual construiu sua casa e instalou sua família no lote que recebera do Governo. Não existem, fora da vila, aglomerações de casas. Os colonos conservaram sua língua, sua fé e, em grande parte, seus costumes; desta maneira, tem-se a impressão de viver numa localidade do norte da Itália (1976, p. 227).

A organização da vida religiosa nas colônias foi bem-recebida pelos italianos, uma vez que o número de religiosos era reduzido desde a criação da colônia, o que explicava a exigência por parte da população em ter, por meio desses missionários, atendimento religioso. Quando o frei chega à Colônia Conde D'Eu e dá início às práticas religiosas, permitidas pela província, escreve ao seu orientador que os colonos são muito generosos e que em cinco meses, "sem contar as missas não ditas, nós fizemos uma receita de mais de 1600 francos. Parece que os bens temporais não serão jamais um problema aqui" (Gillonnay, 2007, p. 35).

Essa primeira reação se explica pelo fato de os colonos se sentirem protegidos por esses missionários que traziam conforto espiritual. Além da confissão, que era a maior solicitação dos colonos, atendiam os doentes, o que representava, muitas vezes, um longo deslocamento a cavalo, devido às distâncias entre as moradias, como relata:

Lá bem longe, nos confins de uma colônia, se agonizasse um pobre trabalhador em sua choupana solitária, imediatamente era necessário montar a cavalo e levar, oculto sobre o coração, o Santo Viático, viajar de dia e de noite, sob o calor e a chuva, por caminhos impraticáveis, através da espessa floresta virgem, durante dias e noites inteiras, a fim de consolar um pobre irmão agonizante, purificar-lhe a alma (Gillonnay; D'apremont, 1976, p. 228).

O reconhecimento do trabalho religioso permitiu pensar na fundação de uma escola seráfica, que pudesse multiplicar as ações que eram inicialmente feitas por dois missionários e, mais tarde, por quatro. Relata na carta de 14 de dezembro de 1896, que matéria-prima existe, e que "as famílias dos imigrantes são numerosas e sentir-se-ão 
honradas em dar um dos seus filhos a Deus". Descreve, ainda, que os pretendentes são "fortes, vigorosos, inteligentes. Crescidos na liberdade da floresta, eles têm o amor da independência; mas tomando-os jovens e submetendo-os a uma forte disciplina, creio que conseguiremos suavizá-los." (Gillonnay; D’apremont apud Costa; De Boni, 1996, p. 24).

Na carta de 16 de julho de 1896, enviada de Conde D’Eu, Frei Bruno tece vários comentários sobre a fundação da comunidade religiosa de Conde D'Eu, baseada na experiência de Ghazir. Nessa carta, o frei solicita ao superior que o mesmo lhe envie os documentos pontífices que regem suas ações já que as concessões pontificias são regidas pela Bula "Romanos Pontífices e os Statuta Missionum" e os freis não a conhecem. Nessa mesma carta, junto à demanda de documentos, solicita ao superior que lhe envie uma farmácia portátil com um formulário para se guiar nas principais enfermidades, que custam, em Marselha, 60 francos. A justificativa está que em Conde D'Eu “não há nem médico nem farmácia”. (Gillonnay, 2007, p. 39). De certa forma, os comentários envolvem remédios para a alma e para o corpo.

$\mathrm{Na}$ carta de 19 de setembro de 1896, as impressões versam sobre os problemas da paróquia, onde, pela primeira vez, aparecem conflitos em relação a alguns párocos e à Maçonaria. Mas a grande preocupação é fundar uma escola de religiosas que possam cuidar da educação das crianças, orientadas por princípios religiosos. Essa intenção permanece até o ano seguinte quando, por meio de uma comissão, são pensadas as condições para instalação de religiosas em Conde D'Eu.

A ideia de trazer religiosas para ocupar um espaço educativo aparece em várias argumentações como favoráveis às mesmas pelo fato de a comunidade ter se comprometido em providenciar: lugar para viver, renda para se sustentar, funções para desempenhar, inclusive, com sugestão de abertura de um pensionato. Entre as condições citadas, manifesta-se o desejo de que sejam cinco religiosas incluindo, entre elas, uma enfermeira.

O único poder imperativo que aparece nas cartas é que todas deveriam saber italiano, e algumas, ainda o português. Os comentários tecidos por Frei Bruno são estruturados no sentido de solicitação de orientação e mostram sua humildade no que diz respeito à forma como registra suas posições e como vê a sociedade. Ressalta, também, a chegada de outras congregações que vêm para a América com o mesmo intuito que o seu. Comenta a chegada da congregação de São Carlos, de Piacenza, Itália, fundada especialmente para os colonos italianos fixados na América. 
Esses religiosos se instalam nas colônias de Alfredo Chaves, local onde deveria ser fundado o primeiro convento capuchinho na zona colonial. Ao tomar conhecimento, Frei Bruno escreve a esse religioso de Piacenza, chamado Pe. Pedro Colbalchini, "fazendo-lhe ver os inconvenientes de ter duas congregações diferentes em lugares tão próximos" (Gillonnay, 2007, p. 53).

A posição de ambos difere sobre essa situação, como aparece com evidência na carta de Frei Bruno enviada ao provincial:

Eu concluía que nós devíamos nos pôr de acordo para trazer uma só e única congregação. Ele me respondeu dizendo-me que lhe parecia que as italianas estariam melhor entre os italianos, que se eu podia deveria mandar as francesas não mais virem (Gillonnay, 2007, p. 53)

Em julho de 1898, foi fundada a escola com mais de vinte jovens que queiram seguir os princípios dessa congregação e compartilhar as lições de São Francisco. Nesse meio tempo, os estudantes que estavam no Líbano, da Província de Saboia, cumprindo o Serviço Militar imposto pelo governo francês, fugiram de uma epidemia de febre tifóide e vieram para o Brasil.

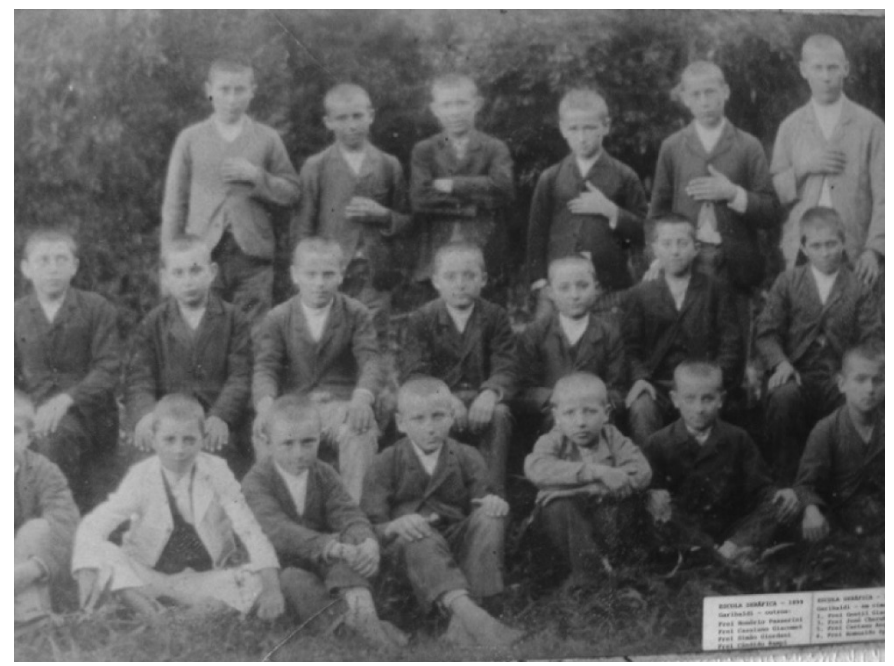

Figura 1. Escola Seráfica (Conde D’Eu) - Garibaldi 1899 grupo dos primeiros seminaristas "nativos".

Acervo de fotografias do Museu dos Capuchinhos. Caxias do Sul. 2011. 


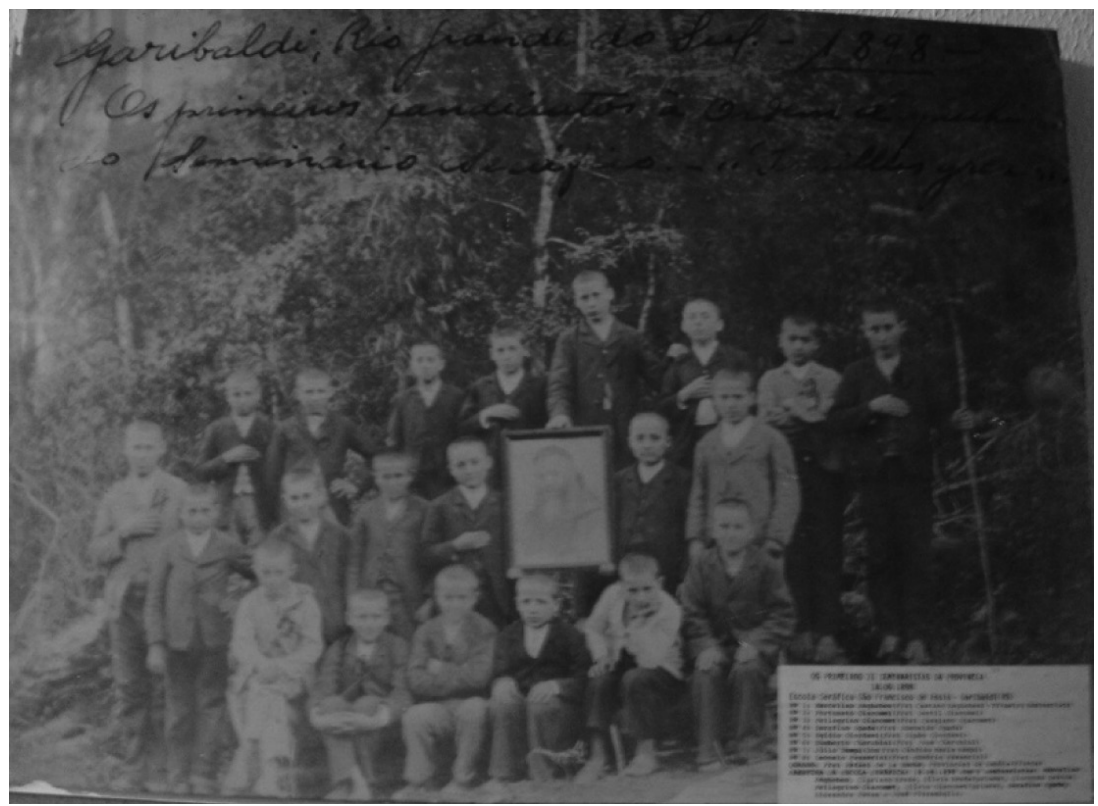

Figura 2. Os primeiros seminaristas da Escola Seráfica do ano de 1898 - Conde D’Eu - (Garibaldi). A Escola Seráfica iniciou dia 18 de junho de 1898 com 9 seminaristas. Acervo de fotografias do Museu dos Capuchinhos. Caxias do Sul. 2011.

A vinda desses jovens missionários fez com que se pensasse em transferir uma parte dos estudantes para Nova Trento. Antes que essa meta se transformasse em realidade, foram construídos novos espaços que permitiram que o convento de Conde D'Eu acolhesse uma comunidade de religiosos que crescia.

A chegada em 1898 dos estudantes, dos padres e dos noviços da Província de Saboia, em Porto Alegre, mostra o clima religioso na capital da província. Monsenhor Balém (1949) revela a visão que os próprios religiosos tinham da situação conforme depoimento transcrito:

Dom Cláudio enviou o jovem José Ricaldone a recebê-los no porto e trazê-los para o seminário. Devia fazê-lo em grupos separados, uns pela rua Gal. Câmara, outros, pela Rua João Manoel, a fim de não chamar muita atenção do povo, como se fosse uma procissão de frades, pois a cidade andava infestada de elementos desordeiros e anti-clericais, haja vista a tentativa de assalto ao seminário e ao convento do Carmo, pouco tempo antes. Mas, nem assim escaparam a uma recepção de batatas podres ao passarem por alguns armazéns, 
onde causava estranheza essa nova espécie de frades de barba, de capuz e pés descalços (Costa; De Boni, 1996, p. 26).

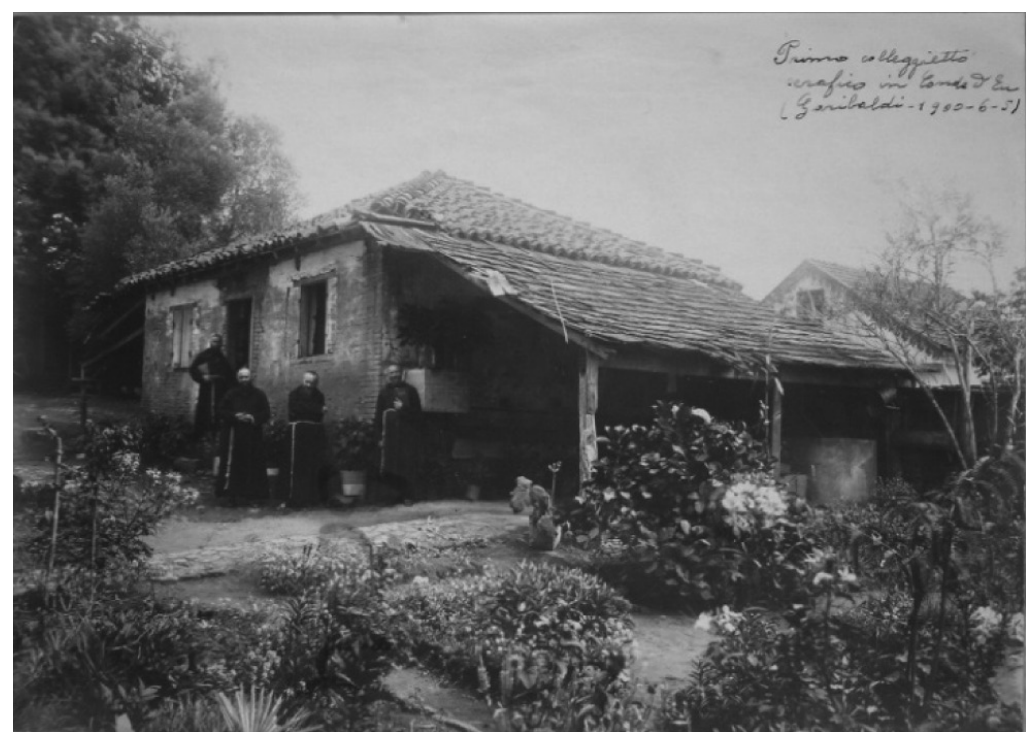

Figura 3. Escola Seráfica de Conde D'Eu - chamada de “La Sorbonne” pelos freis estudantes de Teologia que vinham da França - 1929.

Acervo de fotografias do Museu dos Capuchinhos. Caxias do Sul. 2011.

Além de realizar as ações previstas na educação com a fundação de escolas, Frei Bruno Gillonnay pensou, conforme carta de 20 de agosto de 1904, na possibilidade de editar uma revista mensal que pudesse informar aos colonos e às suas famílias acontecimentos que estavam ocorrendo no mundo, sobre as escolas e sobre o Evangelho. Essa ideia só se concretiza 13 anos depois com a criação do jornal Il Colono Italiano e alguns anos mais tarde, em 1921, quando passa a exercer a direção da congregação, modificando o nome para La Stafetta Riograndense.

Concluindo, constata-se que a ação desse missionário foi decisiva na fundação da missão capuchinha no Rio Grande do Sul e mostra o potencial das colônias italianas, o papel da instituição religiosa no crescimento dessas colônias, esse vinculado aos aspectos educacional, ético e moral. A obra instalada por esse missionário foi eficaz e duradoura conforme mostra a própria história. 


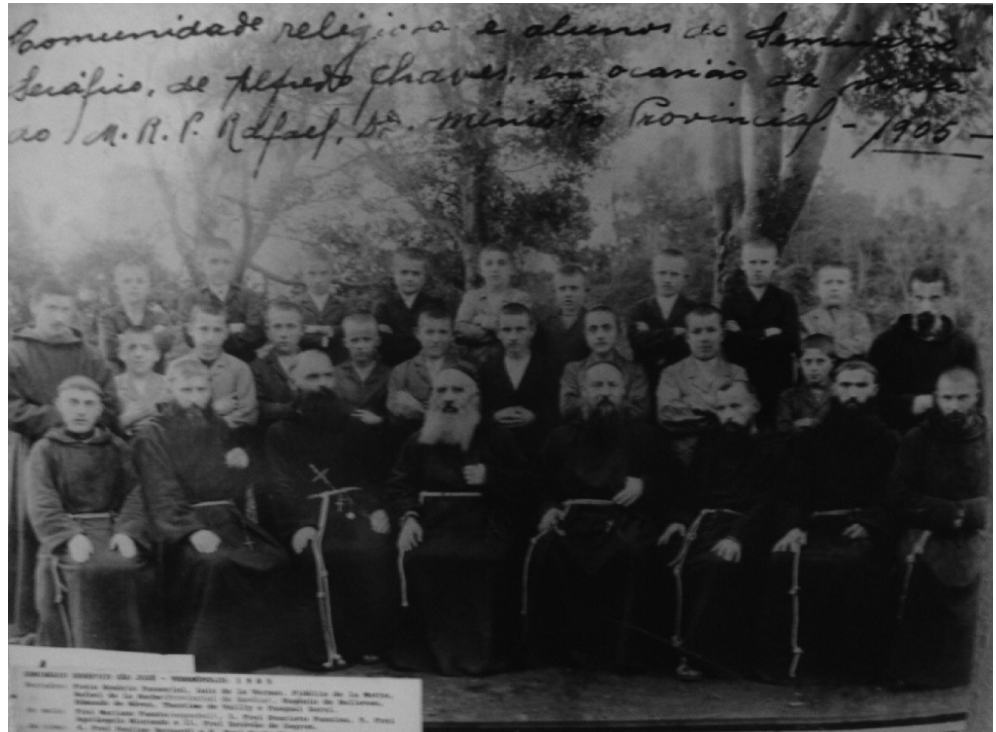

Figura 4. Comunidade Religiosa e seminaristas do Seminário Seráfico de Alfredo Chaves (Veranópolis) por ocasião da visita do Ministro Provincial da Sabóia - Frei Rafael de La Roche - 1905.

Acervo de fotografias do Museu dos Capuchinhos. Caxias do Sul. 2011.

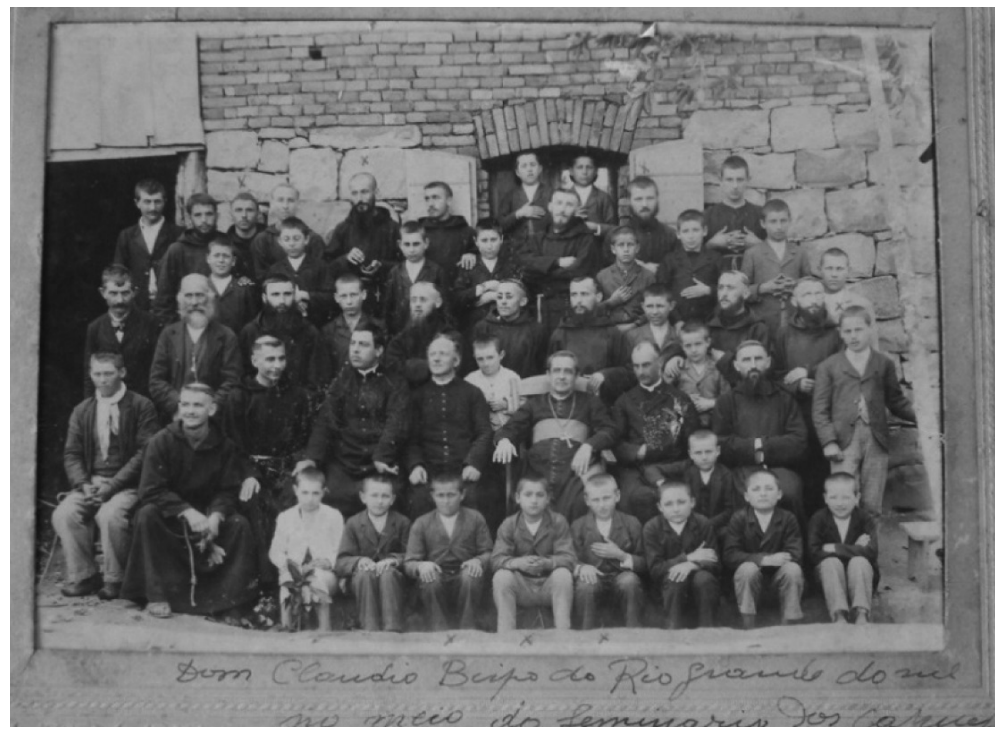

Figura 5. Dom Claudio Ponce de Leon - Seminário São José de Alfredo Chaves Veranópolis.Acervo de fotografias do Museu dos Capuchinhos. Caxias do Sul. 2011. 


\section{Referências}

COSTA, Rovílio; DE BONI, Luis A. Os Capuchinhos do Rio Grande do Sul. Porto Alegre: EST; Caxias do Sul: Correio Riograndense, 1996.

D’APREMONT, Bernardin; GILlONNAY, Bruno de. Comunidades indigenas, brasileiras, polonesas e italianas no Rio Grande do Sul: 1896-1915. Porto Alegre: EST; Caxias do Sul: Educs, 1976.

DE BONI, Luis A.; COSTA, Rovílio. Os italianos no Rio Grande do Sul. 3. ed. Porto Alegre: EST; Caxias do Sul: Educs, 1984.

GILlONNAY, Frei Bruno de. A Igreja e os Capuchinhos do Rio Grande do Sul: 18951909. Trad. de Vanildo Luiz Zugno. Porto Alegre: EST, 2007.

GIRON, Loraine Slomp; HERÉDIA, Vania Beatriz M. História da imigração Italiana no Rio Grande do Sul. Porto Alegre: EST, 2007.

LAZZAROTTO, Danilo. Os Capuchinhos na história e no desenvolvimento de Ijuí. Porto Alegre: EST, 1981.

MAFFIOLETTI, Gianmario; SANFILIPPO, Matteo. (Org.). Un grande viaggio: oltre... un secolo di emigrazione italiana: Saggi e testimonianze in recordo di Padre Gianfausto Rosoli. Roma: Centro Studi Emigrazione, 2001.

MANFROI, Olívio. A colonização italiana no Rio Grande do Sul: implicações econômicas, políticas e culturais. Porto Alegre: Grafosul; Instituto Estadual do Livro, 1975. 
